\title{
Finite element study on the predicted equivalent stresses in the artificial hip joint
}

\author{
Mamdouh M. Monif
}

Department of Biomedical Engineering, Faculty of Mechanical and Electrical Engineering, Damascus University, Damascus, Syria Email: monif65@hotmail.com

Received 16 May 2011; revised 1 June 2011; accepted 20 July 2011

\begin{abstract}
The subsurface fatigue that occurs in the Ultra-High Molecular Weight Polyethylene (UHMWPE) hip joint cup has been identified to be correlated with the contact stress at that cup. This cup stress is known to be affected by the implant design, dimensions and materials. In this study, a 3D finite element modeling has been used to investigate the effects on the cup contact stress when using low stiffness Titanium alloy (Ti) as a femur head. Also, the effects on the cup contact stress due to using different sizes of femur heads, and the presence of metal backing shell with different thicknesses are studied. The finite element results show that the use of low stiffness Ti alloy femur head results in a significant decrease in the cup contact stress compared with Stainless Steel (SS) and Cobalt Chromium (Co Cr Mo) femur heads. The presence of metal backing shell up to $1 \mathrm{~mm}$ thickness results in a remarkable decrease in the cup contact stresses especially for small femur heads. Finally, the use of larger femur heads, up to $32 \mathrm{~mm}$ diameter, results in significant decrease in the overall predicted hip joint contact. The present results indicate that any changes in design and geometrical parameters of the hip joint have significant consequences in the long term behaviour of the artificial hip joint and should be taken into consideration.
\end{abstract}

Keywords: Finite Element Modeling; Hip Joint; UHMWPE; Femur Head Dimensions

\section{INTRODUCTION}

The artificial hip joint arthroplasty involves the replacement of the natural femoral head by a ball made of metallic alloy or ceramic material, and the acetabulum by a polymeric hemispherical lining (Figure 1) [1]. The longterm behaviour of the total hip joint replacement is dependent on obtaining low wear rate within the hip joint polymeric cup [2-7]. The hip joint cup is usually made of
UHMWPE due to its good mechanical properties and excellent biocompatibility [8-13]. In some hip joint designs, and in order to stiffen up the UHMWPE cup and get a more even distribution of contact stresses over the entire surface of UHMWPE cup, metal backing shell has been inserted between the cup and pelvic bone. Also, this metal backing can help in avoiding the loosening of the artificial acetabulum that may be caused by the creep of UHMWPE cup [14-16].

According to clinical results, there are lots of reasons that cause artificial hip joints failure. These include infection, dislocation, stem fracture, loosening, etc. The loosening due to the wear of polymeric cup has been considered as one of the main factors that affects the long-term stability of the total hip arthroplasty. It is believed that the production of wear debris may induce adverse tissue reaction that may lead to extensive bone loss around the implant and consequently osteolysis and implant loosening $[7,14,17]$.

It is known that under high stress levels in artificial hip joints, the UHMWPE cup subsurface fatigue contributes to the volume of wear debris. Since the fatigue process is influenced by surface stress levels, it is becoming increasingly important to reduce contact stress at the cup with the aim of reducing the UHMWPE cup wear debris volume [18-21]. Previous studies indicate

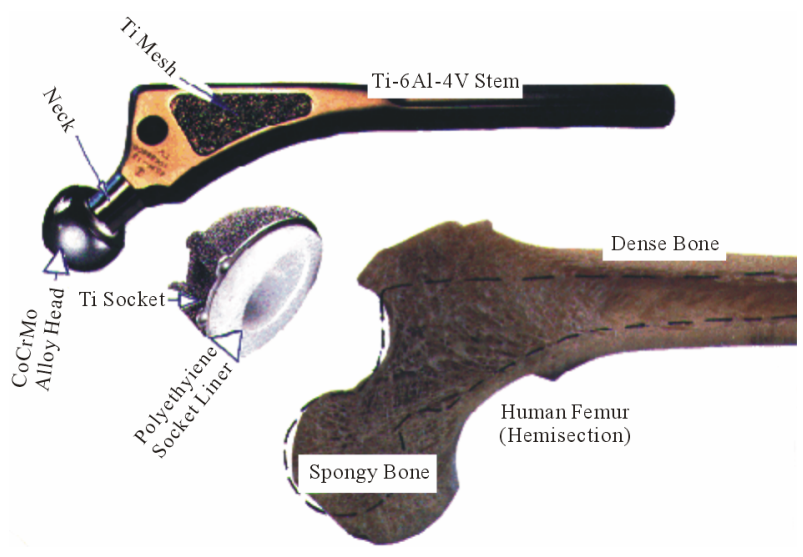

Figure 1. Artificial hip joint model. 
that the femur head dimensions and material, polymeric cup thickness and material, and metal backing shell thickness and stiffness are the most important factors that affect the contact pressure on the cup [22-25]. Therefore, over the past few decades, different artificial hip joint designs have been demonstrated to modulate implant survival [26-28]. However, the combined effects of the hip joint design parameters on the resultant contact pressure on the polymeric cup are still unclear. Moreover, studying the combined effects of all these hip joint design parameters at the same time may result in modification of UHMWPE contact pressure, and affect the long term performance of the hip implant.

The present study attempts to improve the long term performance of the total hip joint replacement through using low stiffness Ti as a femur head. A 3D finite element modeling has been used to investigate the changes in the UHMWPE cup predicted Von Mises stress. This investigation is done by using low stiffness Ti alloy as femur head instead of traditional femur heads made of SS and Co Cr Mo for un-cemented hip joint under static loading conditions. Also, this study considers the effects of femur head dimensions on the resultant contact pressure at the hip joint cup in the presence of $0.1 \mathrm{~mm}$ radial clearance between ball and cup. The effects of the presence of a metal backing shell of different thicknesses on the UHMWPE contact stress will also be studied. The main aim of this study is to reduce the contact stresses at the UHMWPE cup that are thought to play an important role in the long term clinical performance of the artificial hip joint prostheses.

\section{FINITE ELEMENT MODEL}

In the present study, the 3D finite element models of the artificial hip joint prostheses are generated by using the finite element code ANSYS v12 [29]. This implicit nonlinear finite element code is used in this study because of its efficiency for linear and non-linear quasi-static simulation. Three different femur head geometries (22, 28 and $32 \mathrm{~mm}$ ) are considered. The dimensions of femur heads, UHMWPE cups and metal backing shell are tabulated in Table 1 [30]. The pelvis is assumed to have a hemispherical shape with $42 \mathrm{~mm}$ thickness of cancellous bone [14]. Figure 2 schematically shows the hip joint model consisting of femur head, UHMWPE cup, different metal backing shells, and finally the pelvis bone.

In the first hip joint model, the artificial hip joint contains pelvic bone, and femur head with different materials and dimensions and their corresponding UHMWPE cups. The second model is similar to the first model except that metal backing shell with different thickness ( 0 , 1,2 and $3 \mathrm{~mm}$ ) covers the cup. For all models, a radial clearance of $0 \mathrm{~mm}, 0.1 \mathrm{~mm}$ and $0.25 \mathrm{~mm}$ between the
Table 1. Hip joint dimensions (mm).

\begin{tabular}{cccc}
\hline Femur Head & $\begin{array}{c}\text { UHMWPE Cup } \\
\text { Inner Diameter }\end{array}$ & $\begin{array}{c}\text { UHMWPE Cup } \\
\text { Thickness }\end{array}$ & $\begin{array}{c}\text { Metal Backing } \\
\text { Thickness }\end{array}$ \\
\hline 22 & $22,22.1,22.25$ & 15 & $0,1,2,3$ \\
28 & $28,28.1,28.25$ & 15 & $0,1,2,3$ \\
32 & $32,32.1,32.25$ & 15 & $0,1,2,3$ \\
\hline
\end{tabular}
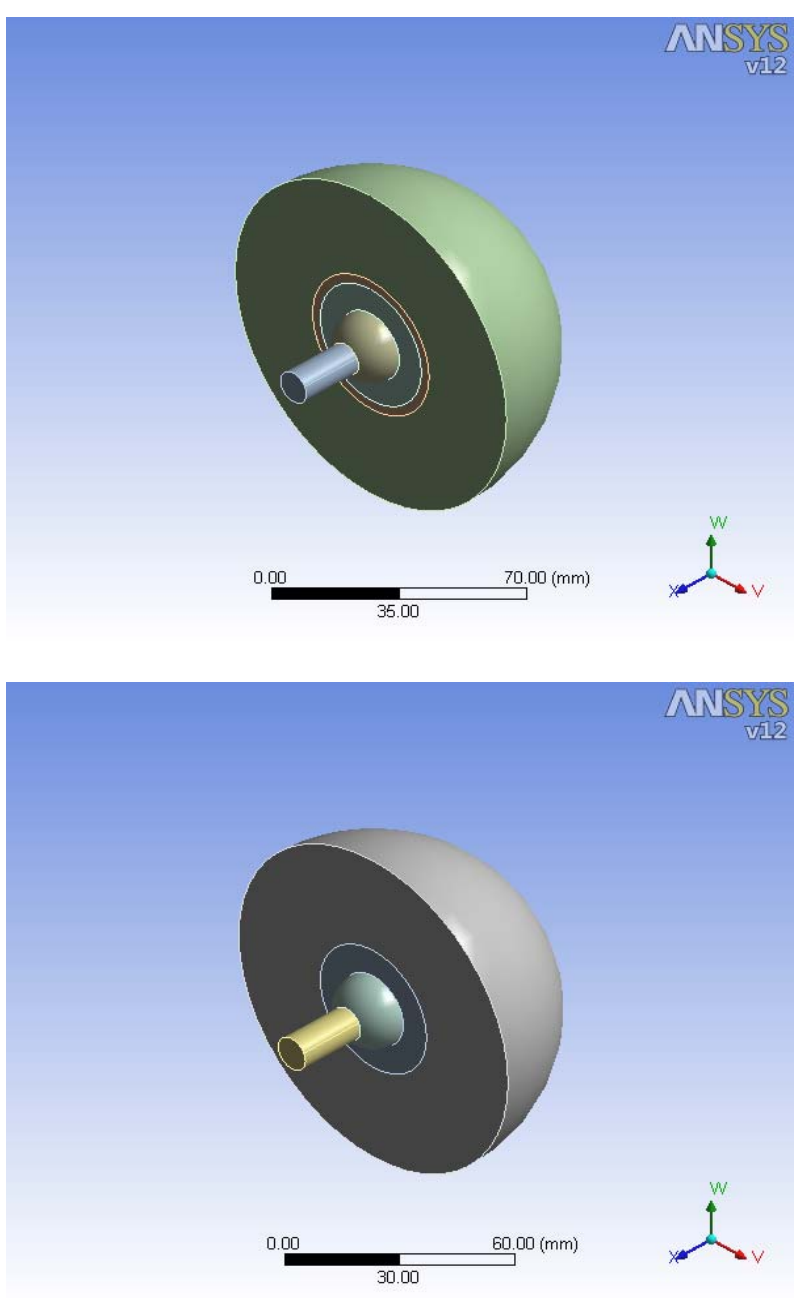

Figure 2. Hip joint finite models.

femur head and cup has been taken into consideration. A 3-D 20 node solid element (tetrahedron Solid 95) is chosen for modeling the hip joint assembly. This element is defined by 20 nodes that have three degrees of freedom at each node. This element has quadratic displacement behaviour and is well-suited to model regular and irregular meshes. Also, this element has the capability to accurately model the plastic deformation, creep, large deflecttion, and large strain that may occur during the simulation. The effects of mesh size and density on the predicted results are examined by increasing the number 
of elements until the predicted results become constant with increasing the mesh density.

\section{MATERIALS PROPERTIES}

Five different materials are used in the present finite element simulation: New BETA type low-rigidity titanium alloy low elastic modulus of $58 \mathrm{GPa}$, fatigue strength of $700 \mathrm{MPa}$ [31], and Cobalt Chromium (Co Cr Mo) and Stainless Steel (SS) are used to simulate metallic femur heads due to their high strength and sufficient biocompatibility in clinical conditions. UHMWPE is selected to represent the cup material due to its relatively good wear resistance. The SS is used as the metal backing shell material due to its high strength. Finally, the pelvis, which is assumed as a hemispherical shape, is represented as a cancellous bone [14]. The materials of the hip joint components are assumed to be homogenous, isotropic and linearly elastic. The values of elastic modulus and Poisson's ratio of the hip joint materials are summarized in Table 2 [14,22,23,28,31].

\section{APPLICATION OF LOADS AND CONSTRAINS}

The hip joint model is fixed superiorly at the ilium, and a fixed load of $3 \mathrm{KN}$, which corresponds to 3 - 5 times body weight, is applied at the femur head neck. This resultant load is based on the assumption that the body weight is $70 \mathrm{Kg}$. Other initial conditions like sex, age, activity, etc. are neglected [23]. The contact interface between the UHMWPE cup, metal backing shell, and pelvic bone is represented as completely bonded surfaces. On the other hand, the interface between the femur head and UHMWPE cup is simulated as a frictionless contact.

\section{RESULTS AND DISCUSSIONS}

\subsection{Effects of Femur Head Dimension and Stiffness on the UHMWPE Stresses}

Figure 3 shows the predicted maximum Von Mises stresses induced on the UHMWPE cup for different femur head geometries and materials. The results indicate that the maximum Von Mises stress at the UHMWPE cup decreases significantly by increasing the femur head diameter for all types of femur head materials. With regards to the Ti alloy femur head, the stress at the cup decreases from 21 to $14 \mathrm{MPa}$ when a femur head of 32 $\mathrm{mm}$ diameter is used instead of $22 \mathrm{~mm}$. For SS femur head, the stress at the cup decreases from 25 to $18.8 \mathrm{MPa}$ when the femur head of $32 \mathrm{~mm}$ diameter is used instead of $22 \mathrm{~mm}$. Finally, for Co Cr Mo femur head, the stress at the cup decreases from 27 to $19.5 \mathrm{MPa}$ when a femur head of $32 \mathrm{~mm}$ diameter is used instead of $22 \mathrm{~mm}$. The significant decrease in the UHMWPE cup stress due to using larger femur heads can be attributed to the increase in the contact area between the femur head and the cup

Table 2. Hip joint material properties.

\begin{tabular}{ccc}
\hline Material & Elastic Modulus GPa & Poisson's Ratio \\
\hline Titanium alloy & 58 & 0.3 \\
Cobalt Chromium Alloy & 230 & 0.3 \\
Cortical Bone & 17 & 0.3 \\
SS & 210 & 0.3 \\
UHMWPE & 1.2 & 0.4 \\
\hline
\end{tabular}

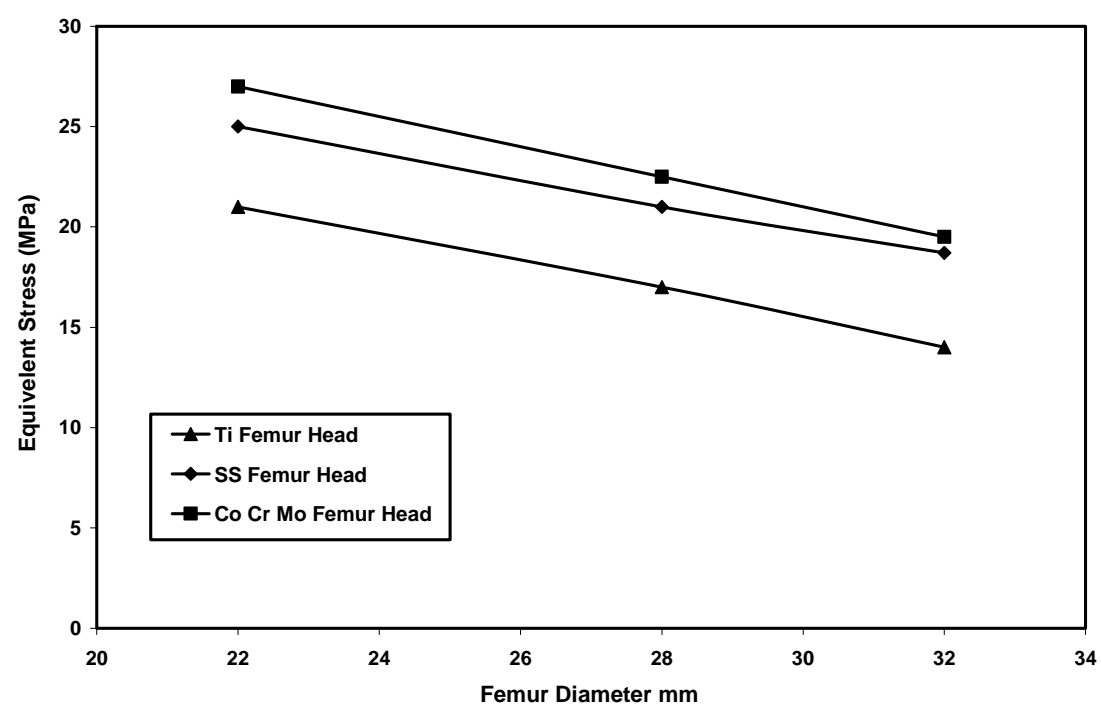

Figure 3. Variation of UHMWPE cup Von Mises stress with femur head diameter and materials for non metal backed hip joint. 
which is inversely dependent on the femur dimension.

According to the results above, it can be remarked that for $22 \mathrm{~mm}$ femur head, the values of maximum Von Mises stresses on the UHMWPE cup are $27 \mathrm{MPa}, 25$ MPa and 21 MPa for Co Cr Mo, SS and Ti head heads respectively. These values (except for Ti femur head) are higher than the yield strength of UHMWPE material which is around 23.5 MPa [10-13]. The presence of such local higher stress zones will affect subsurface fatigue of the UHMWPE cup, which contributes to aspect joint loosening. For $32 \mathrm{~mm}$ femur head, the maximum values of Von Mises stress on the UHMWPE cup are less than its yield strength for all femur head materials.

Also, it can be remarked from this figure that the resultant stresses on the UHMWPE cup decrease significantly when using Ti femur head instead of SS and Co Cr Mo. This decrease can be attributed to the low stiffness of Ti femur head compared to other femur heads. For $22 \mathrm{~mm}$ femur head, the resultant Von Mises stress on the UHMWPE cup decreases by $22 \%$ when using low stiffness Ti femur head instead of Co Cr Mo. For 32 femur head, the resultant Von Mises stress on the UHMWPE cup decreases from 19.5 MPa to $14 \mathrm{MPa}$ when using Ti femur head instead of Co Cr Mo. However, the Ti alloy femur head with modulus equals $58 \mathrm{GPa}$ results in a decrease in the UHMWPE cup Von Mises stress compared to other femur heads due to its high flexibility. This decrease in the UHMWPE contact stresses may lead to an improvement in the short and long term performance of the hip joint implant $[17,21]$.

\subsection{Effects of Metal Backing Thickness on the UHMWPE Stresses}

The effects of the metal backing shell thickness on the predicted maximum Von Mises stresses on the UHMWPE cup are shown in Figure 4. It can be noticed from the result that the stresses on the cup decrease due to the presence of SS metal backing up to $1 \mathrm{~mm}$ thickness. Beyond $1 \mathrm{~mm}$ thickness, the stresses at the cup reach a constant value and become independent of the metal backing thickness. There is no need to increase the metal backing shell thickness beyond $1 \mathrm{~mm}$ in the artificial hip joint system. However, the presence of metal backing results in a uniform distribution of Von Mises stresses at the UHMWPE cup.

For $22 \mathrm{~mm}$ Ti alloy femur head, stresses at the UHMWPE decrease from 21 to 19.9 and to $19.7 \mathrm{MPa}$ when $1 \mathrm{~mm}$ and $3 \mathrm{~mm}$ metal backing shell is used respectively. For the SS femur head, the cup stresses decrease from 25 to 23.5 and to $23.4 \mathrm{MPa}$ when $1 \mathrm{~mm}$ and $3 \mathrm{~mm}$ metal backing shell is used respectively. Finally, for the Co $\mathrm{Cr}$ Mo femur head, the stresses at the UHMWPE cup decrease from 27 to 26 and to $25.8 \mathrm{MPa}$ when $1 \mathrm{~mm}$ and 3 mm metal backing shell is used respectively. Similar results have been obtained by Hia-bo J. [22] where the UHMWPE cup stresses decrease by $10 \%$ when using SS as a metal backing for Ti and Co Cr Mo femur heads.

\subsection{Effects of Radial Clearance on the UHMWPE Stresses}

It is known that the radial clearance between the femur and cup results in a decrease of both wear rate and fraction coefficient in the hip implant. Therefore, the hip joint designs include a radial clearance between the femur and the cup $[17,30]$. Figures 5(a)-(c) shows the effects of the presence of a gap between the UHMWPE cup and femur on the resultant Von Mises stress on the cup for a different femur dimension and material. From Figure 5(a), it can be noticed that for Ti femur with 22 $\mathrm{mm}$ diameter, the cup stress increases from 21 to 35.3 MPa due to the presence of $0.25 \mathrm{~mm}$ gap. For $32 \mathrm{~mm}$ femur head, the cup stress increases from 14 to $23.5 \mathrm{MPa}$ due to the presence of $0.25 \mathrm{~mm}$ gap.

Figure 5(b) shows the variation of UHMWPE Von Mises stress with different SS femur head in the presence of a gap between femur head and cup. Again, the cup Von Mises stress increases from 25 to $41.2 \mathrm{MPa}$ due to the presence of a $0.25 \mathrm{~mm}$ gap for a $22 \mathrm{~mm}$ femur head. For Co Cr Mo femur with $22 \mathrm{~mm}$ diameter, the cup stress increases from 27 to $44 \mathrm{MPa}$ due to the presence of a $0.25 \mathrm{~mm}$ gap (Figure 5(c)). For $32 \mathrm{~mm}$ femur head, the cup stress increases from 19.5 to $31 \mathrm{MPa}$ due to the presence of a $0.25 \mathrm{~mm}$ gap.

The results of Figures 5(a)-(c) show that the Ti, SS and $\mathrm{Co} \mathrm{Cr}$ Mo femur heads have similar trends where the Von Mises stresses increase due to the presence of a gap especially at small femurs dimensions. The increase in the UHMWPE cup Von Mises stress due to the presence of a gap can be attributed to the decrease of the UHMWPE contact area that carries the joint load and hence the peak contact Von Mises Pressure increased.

\subsection{Stresses at Bone}

The relation between the resultant stress at the bone and femur head dimension and material is shown in Figure 6. From these results, it can be remarked that the stress at the bone decreases by increasing the femur diameter due to the change in contact area. Also, the results show that the Ti alloy femur head results in lower stress at the bone compared to other femur heads. The presence of metal backing also results in lower stress at bone especially for a small femur head dimension. The decrease in bone stress due to the presence of metal backing can be attributed to the metal backing carrying part of the load transmitted from the UHMWPE cup to the bone. 


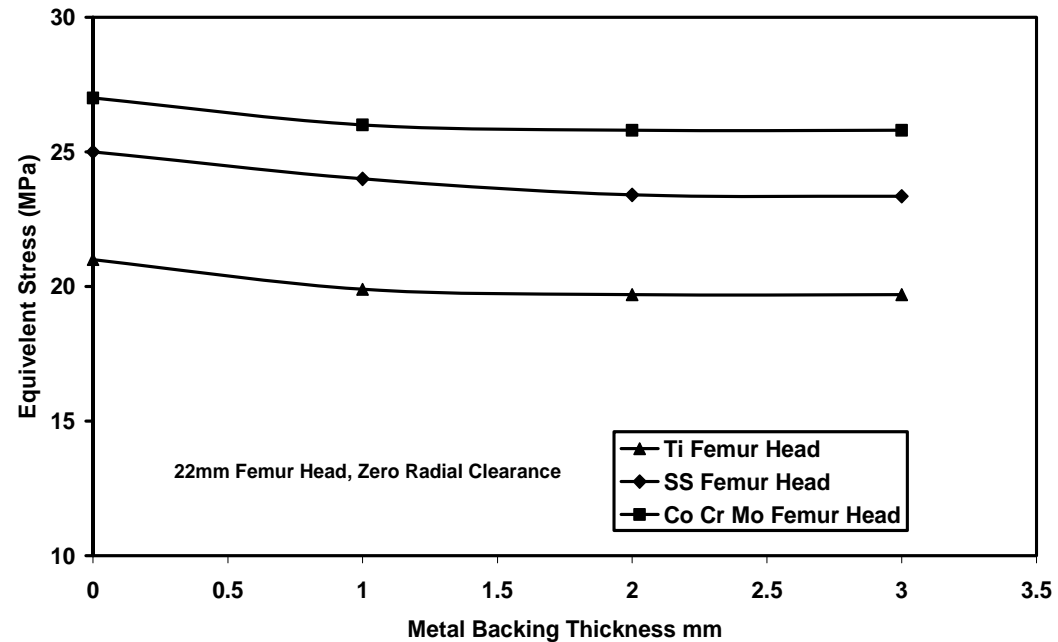

(a)

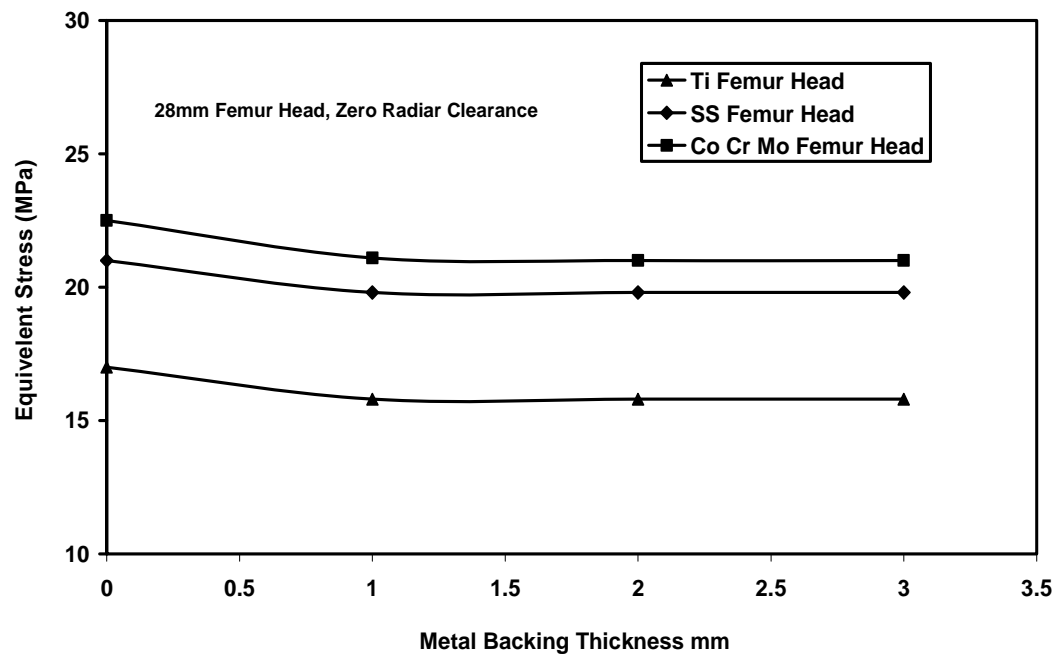

(b)

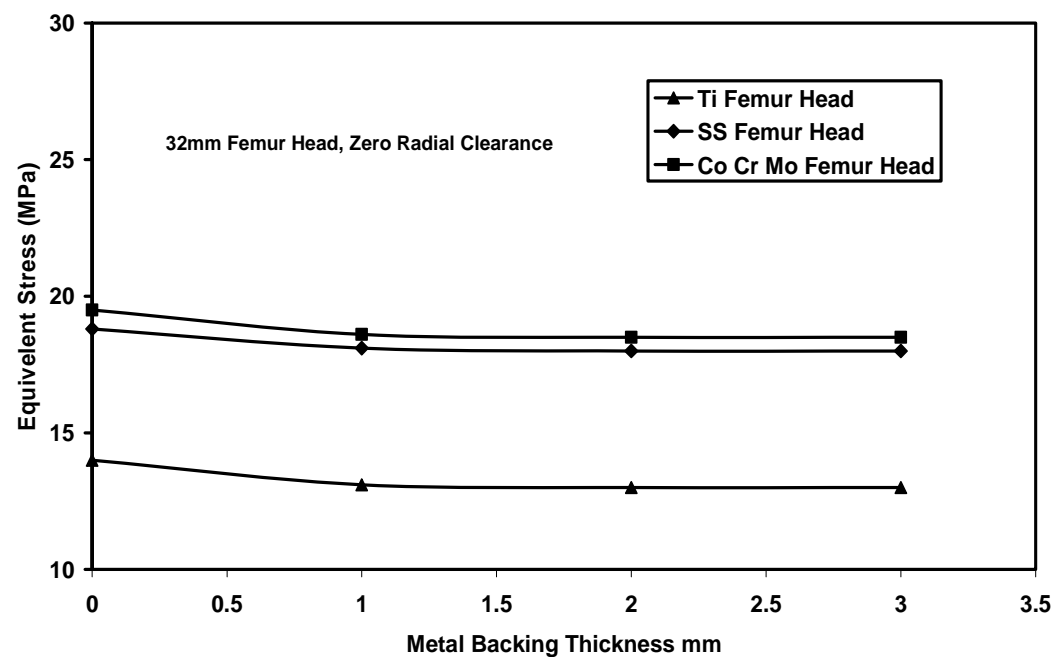

(c)

Figure 4. Effects of metal backing shell thickness on the variation of UHMWPE cup stress with femur head diameter and material. 


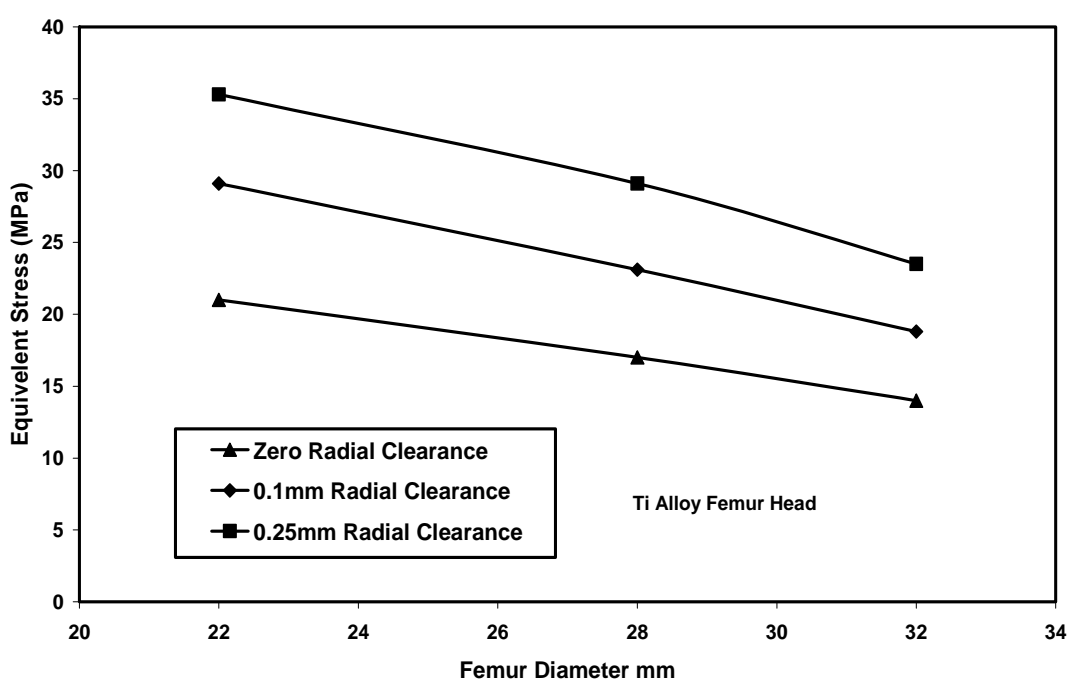

(a)

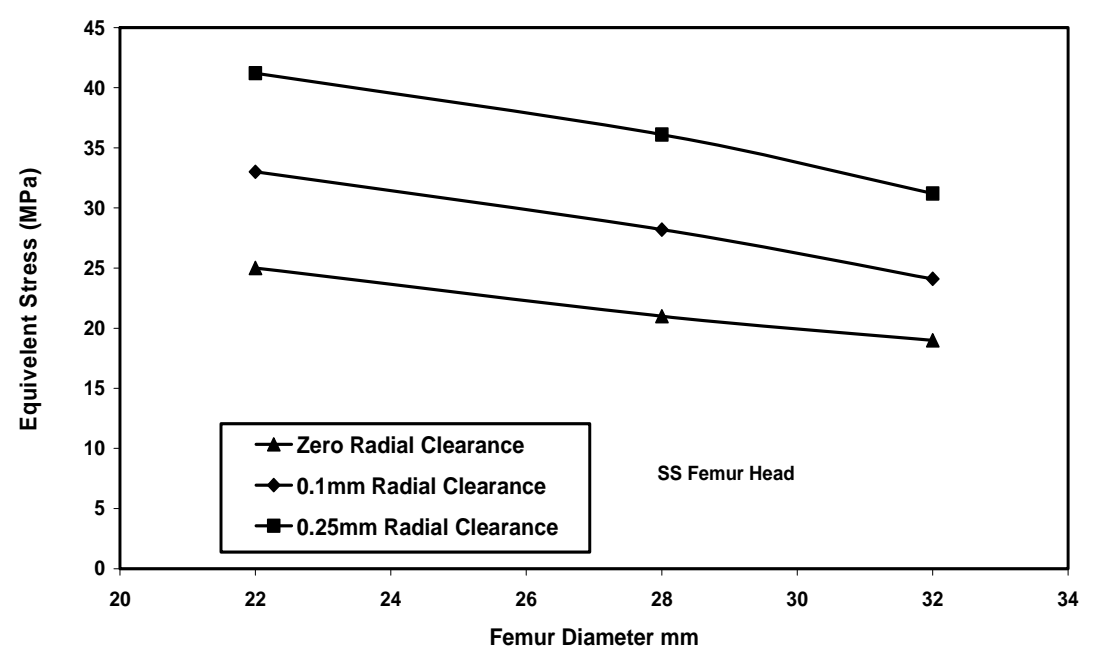

(b)

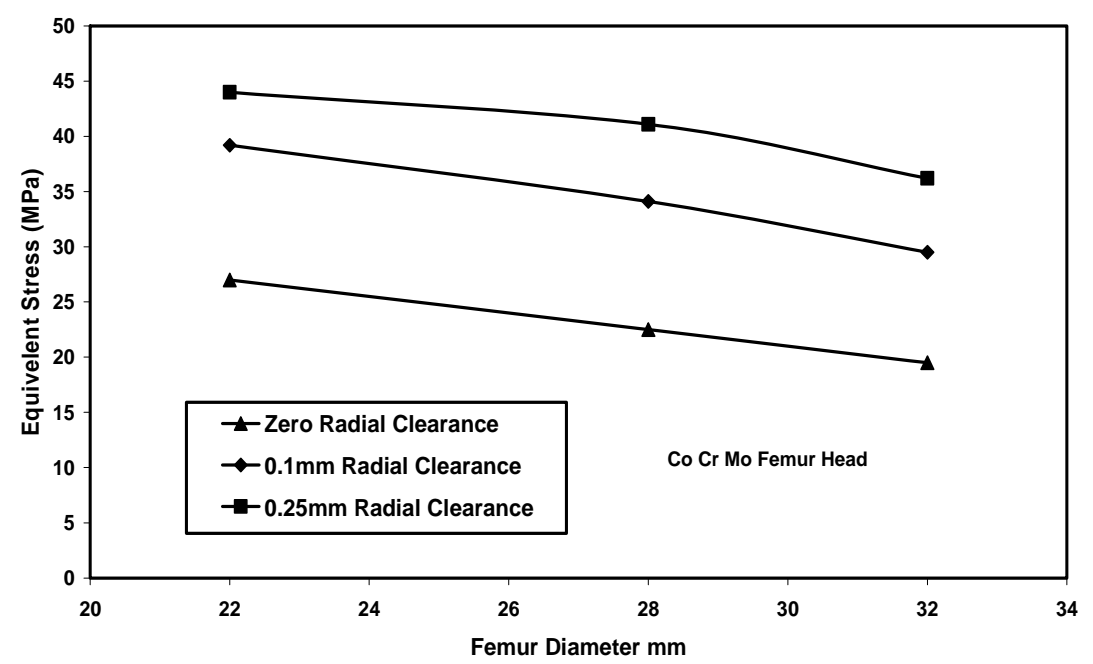

(c)

Figure 5. Effect of radial clearance on the UHMWPE cup stress for different femur head diameters and materials for non metal backed implant. 


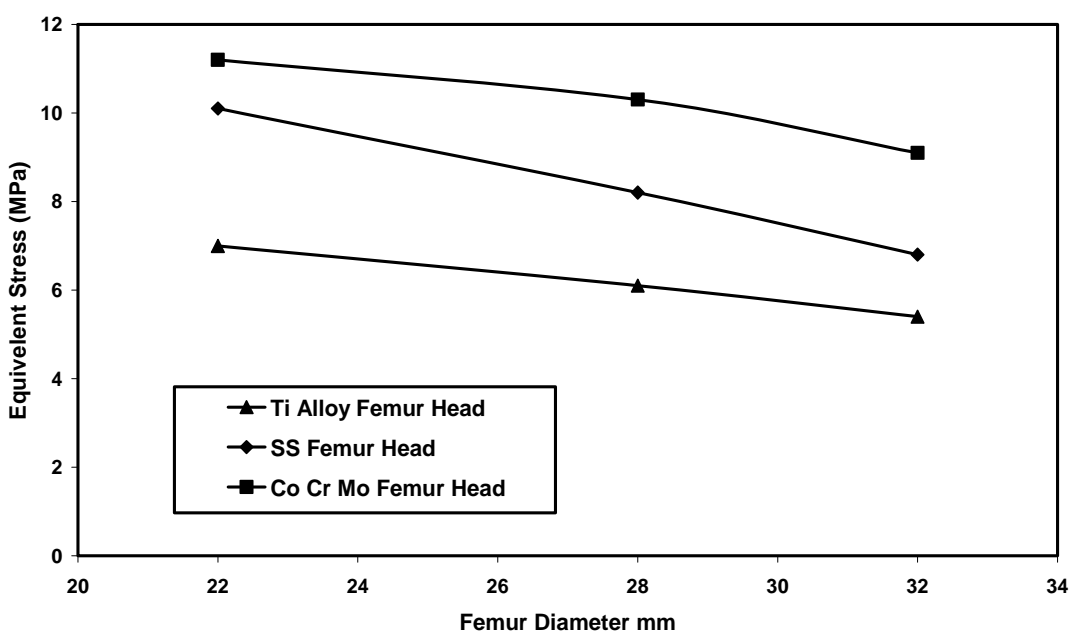

(a)

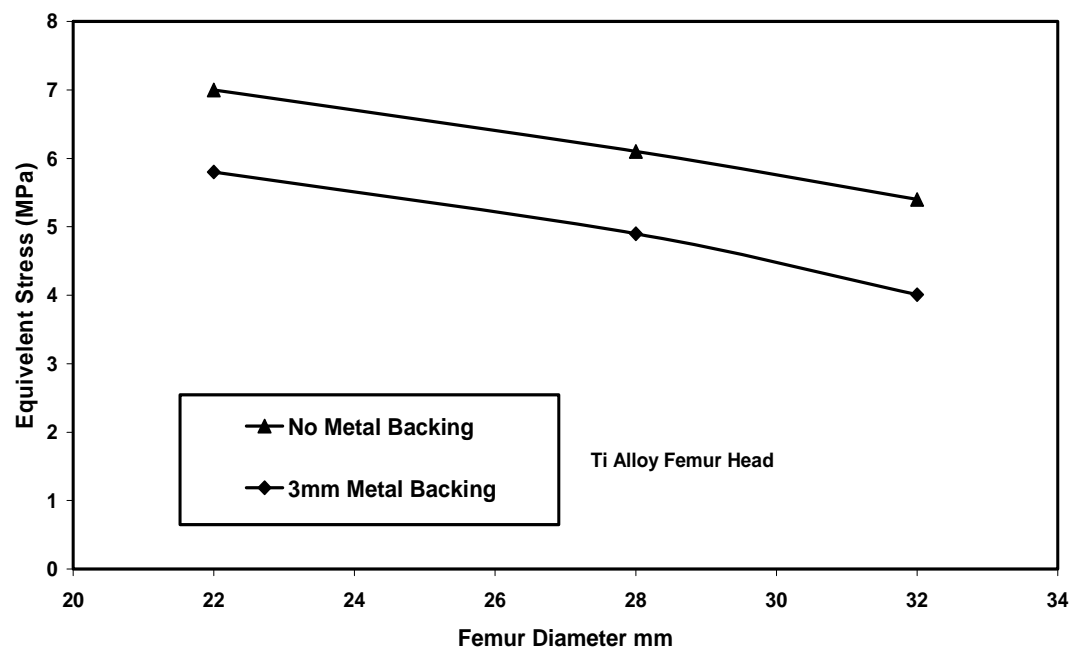

(b)

Figure 6. Variation of bone stress with femur head diameter and materials for metal backed and non metal backed hip joint.

\section{CONCLUSION}

The Finite Element results show that the femur dimension, and material and presence of radial clearance between cup and head have significant effects on the resultant Von Mises stress at the polymeric cup. The use of Ti alloy with low stiffness as a femur instead of Co Cr Mo results in a decrease in the UHMWPE cup Von Mises stress by about 22\% for non metal backed implant with $22 \mathrm{~mm}$ femur head. Also, the use of large femur dimension results in a significant change in the cup stresses. The use of femur with $32 \mathrm{~mm}$ diameter instead of $22 \mathrm{~mm}$ femur results in a decrease of the UHMWPE cup stress by $33 \%, 25 \%$ and $28 \%$ for $\mathrm{Ti}$, SS and Co Cr Mo femur heads respectively. The Finite element results also indicate that the metal backing results in lower stress at the UHMWPE cup up to $1 \mathrm{~mm}$ thickness. Finally, the presence of radial clearance results in a significant increase in the stresses at the UHMWPE cup especially for small femur heads. Therefore, these factors should be taken into consideration in the design of the total hip joint replacement.

\section{REFERENCES}

[1] Teoh, S.H., Chan, W.H. and Thampuran, R. (2002) An elasto-plastic finite element model for polyethylene wear in total hip arthroplasty. Journal of Biomechanics, 35, 323-330. doi:10.1016/S0021-9290(01)00215-9

[2] Saikko, V. and Shen, M. (2010) Wear comparison between a dual mobility total hip prosthesis and a typical modular design using a hip joint simulator. Wear, 268, 617-621. doi:10.1016/j.wear.2009.10.011

[3] Unsworth, A., Scholes, S.C., Smith, S.L., Elfick, A.P.D. and Ash, H.A. (2000) Tribology of replacement hip joints. Tribology and Interface Engineering Series, 38, 195-202. 
[4] Wilches, L.V., Uribe, J.A. and Toro, A. (2008) Wear of materials used for artificial joints in total hip replacements. Wear, 265, 143-149. doi:10.1016/j.wear.2007.09.010

[5] Ilchmann, T., Reimold, M. and Müller-Schauenburg, W. (2008) Estimation of the wear volume after total hip replacement: A simple access to geometrical concepts. Medical Engineering \& Physics, 30, 373-379. doi:10.1016/j.medengphy.2007.04.003

[6] Barnes, C.L., De Boer, D., Corpe, R.S., et al. (2008) Wear performance of large-diameter differential-hardness hip bearings. The Journal of Arthroplasty, 23, 56-60. doi:10.1016/j.arth.2008.05.021

[7] Affatato, S., Bersaglia, G., Rocchi, M., Taddei, P., Fagnano, C. and Toni, A. (2005) Wear behaviour of crosslinked polyethylene assessed in vitro under severe conditions. Biomaterials, 26, 3259-3267. doi:10.1016/j.biomaterials.2004.07.070

[8] Wang, Q.L., Liu, J.L. and Ge, S.R. (2009) Study on biotribological behavior of the combined joint of CoCrMo and UHMWPE/BHA composite in a hip joint simulator. Jour- nal of Bionic Engineering, 6, 378-386.

[9] Furmanski, J., Anderson, M., Bal, S., Greenwald, A.S., Halley, D., Penenberg, B., Ries, M. and Pruitt, L. (2009) Clinical fracture of cross-linked UHMWPE acetabular liners. Biomaterials, 30, 5572-5582.

doi:10.1016/j.biomaterials.2009.07.013

[10] Fouad, H. (2010) Experimental and numerical studies of the notch strengthening behaviour of semi-crystalline ultra-high molecular weight polyethylene. Materials \& Design, 31, 1117-1129. doi:10.1016/j.matdes.2009.09.042

[11] Mourad, A.-H.I., Fouad, H. and Rabeh, E. (2009) Impact of some environmental conditions on the tensile, creeprecovery, relaxation, melting and crystallinity behaviour of UHMWPE-GUR 410-medical grade. Materials \& Design, 30, 4112-4119. doi:10.1016/j.matdes.2009.05.001

[12] Fouad, H., Mourad, A.-H.I. and Barton, D.C. (2005) Effect of pre-heat treatment on the static and dynamic thermo-mechanical properties of ultra-high molecular weight polyethylene. Polymer Testing, 24, 549-556. doi:10.1016/j.polymertesting.2005.02.007

[13] Mohamed, H.F., Mourad, A.-H.I. and Barton, D.C. (2008) UV irradiation and aging effects on nanoscale mechanical properties of ultra high molecular weight polyethylene for biomedical implants. Plastics, Rubber and Composites, 37, 346-352. doi:10.1179/174328908X314370

[14] Griza, S., Cê, A.N., Silva, E.P., Bertoni, F., Reguly, A. and Strohaecker, T.R. (2009) Acetabular metal backed fatigue due to severe wear before revision. Engineering Failure Analysis, 16, 2036-2042. doi:10.1016/j.engfailanal.2009.01.004

[15] Ray, C.W., Joshua, J.J., Barrington, A. and Harry, E.R. (2005) The Acetabular insert-metal backing interface: An additional source of polyethylene wear debris. The Journal of Arthroplasty, 20, 914-922.

[16] Frank, S.C., Paul, E.D.C., Ashay, A.K., Jen, F.L., Victor, H.F., Steven, A.S. and Joseph, D.Z. (1998) Results of cemented metal-backed acetabular components: A 10-yearaverage follow-up study. The Journal of Arthroplasty, 13,
67-873.

[17] Burger, N.D.L., De Vaal, P.L. and Meyer, J.P. (2007) Failure analysis on retrieved ultra high molecular weight polyethylene (UHMWPE) acetabular cups. Engineering Failure Analysis, 4, 1329-1345. doi:10.1016/j.engfailanal.2006.11.005

[18] Korhonen, R.K., Koistinen, A., Konttinen, Y.T., Santavirta, S.S. and Lappalainen, R. (2005) The effect of geometry and abduction angle on the stresses in cemented UHMWPE acetabular cups-finite element simulations and experimental tests. BioMedical Engineering Online, 4, 32. doi:10.1186/1475-925X-4-32

[19] Rixrath, E., Wendling-Mansuy, S., Flecher, X., Chabrand, P. and Argenson, J.N. (2008) Design parameters dependences on contact stress distribution in gait and jogging phases after total hip arthroplasty. Journal of Biomechanics, 41, 1137-1142. doi:10.1016/j.jbiomech.2007.12.009

[20] Bertram, T., Anton, H., Johan, K., Veronika, K., Gunnar, F., Nico, V. and Ron, D. (2008) Association between contact hip stress and RSA-measured wear rates in total hip arthroplasties of 31 patients. Journal of Biomechanics, 41, 100-105. doi:10.1016/j.jbiomech.2007.07.010

[21] Barbour, P.S.M., Barton, D.C. and Fisher, J. (1995) Influence of contact stress on the wear of UHMWPE for total replacement hip prostheses. Wear, 181, 250-257.

[22] Jiang, H.-B. (2007) Static and dynamic mechanics analysis on artificial hip joints with different interface designs by the finite element method. Journal of Bionic Engineering, 4, 123-131. doi:10.1016/S1672-6529(07)60024-9

[23] Bennett, D. and Goswami, T. (2008) Finite element analysis of hip stem designs. Materials \& Design, 29, 45-60. doi:10.1016/j.matdes.2006.12.014

[24] Marianne S. D., Luc W., Siegfried D. and Kai-Uwe, S. (2008) Development of a new design of hip protectors using finite element analysis and mechanical tests. Medical Engineering \& Physics, 30, 1186-1192. doi:10.1016/j.medengphy.2008.02.011

[25] Kang, L., Galvin, A.L., Jin, Z.M. and Fisher, J. (2006) A simple fully integrated contact-coupled wear prediction for ultra-high molecular weight polyethylene hip implants: Journal of Engineering in Medicine, 220, 33-46. doi:10.1243/095441105X69033

[26] Bowsher, J.G., Donaldson, T.K., Willians, P.A. and Clarke, I.C. (2008) Surface damage after multiple dislocations of a 38-mm-diameter, metal-on-metal hip prosthesis. The Journal of Arthroplasty, 23, 1090-1096. doi:10.1016/j.arth.2007.09.007

[27] Elfick, A.P.D., Hall, R.M., Pinder, I.M. and Unsworth, A. (1998) Wear in retrieved acetabular components: Effect of femoral head radius and patient parameters. The Journal of Arthroplasty, 13, 291-295. doi:10.1016/S0883-5403(98)90174-7

[28] Darwish, S.M. and Al-Samhan, A.M. (2009) Optimization of artificial hip joint parameters. Material Science and Engineering Technology, 40, 218-223.

[29] ANSYS Version 12 (2009) ANSYS, Inc., Canonsburg.

[30] Muratoglu, O.K., Bragdon, C.R., O’Connor, D., Perin- 
chief, R.S., Estok, D.M., Jasty, M. and Harris, W.H. (2001) Larger diameter femoral heads used in conjunction with a highly cross-linked ultra high molecular weight polyethylene: A new concept. The Journal of Arthroplasty, 16, 24-30. doi:10.1054/arth.2001.28376

[31] Tomokazu, H., Keizo, M., Shigeo, N., Keiji, S., Mitsuo,
N. and Akihiro, S. (2002) Material rigidity of fracture fixation device and bone tissue reaction. Experimental study on intramedullary fixation with different materials. Proceedings of Annual Meeting of Japanese Society for Orthopaedic Biomechanics, 23, 299-304. 